\title{
Determination of flavomycin residue in grass carp by high performance liquid chromatography
}

\section{TIAN Liang-liang ${ }^{1}$, HUANG Dong-mei ${ }^{1 *}$, SHI Yong-fu ${ }^{1}$, HAN Feng ${ }^{1}$, ZHOU}

\section{Peng ${ }^{1}$ \\ (1. East sea Fisheries Research Insititute,Chinese Academy of Fisheries Sciences, Shanghai 200090,China;)}

Key words:High performance liquid chromatography; grass carp;flavomycin; residues;

Abstract:A method for the determination of flavomycin in shrimp by high performance liquid chromatography was established. Flavomycin in sample was extracted by methanol solution and defatted with n-hexane. The lower was cleaned through the membrane and determined by HPLC. The calibration curve was linear. The method was accurate and reproducible, being successfully applied to the monitoring of flavomycin in grass carp. The recoveries were $83.9 \%-88.2 \%$ in the spiked range of $2.0-50.0 \mathrm{mg} / \mathrm{kg}$ in grass carp. The relative standard deviation was below $10.4 \%$. The limit of detection for this method as defined by ten times signal to noise was $2.0 \mathrm{mg} / \mathrm{kg}$.

Flavomycin known as bambermycin, moenomycin is Phosphoric acid polysaccharide antibiotics which is separated from the fermented product of grey green streptomycin bacteria (bambermycin chain thermosphacta). Flavomycin can inhibit bacteria reproduction by interfering with a cell wall peptidoglycan structure material biosynthesis. Flavomycin is effective for most gram-positive bacteria and some gram-negative bacteria. Flavomycin is a new kind of antibiotic drug additives and growth promoting agent.

Flavomycin contains at least five kinds of active ingredients, and its main active group is divided into flavomycin $\mathrm{A}$. The detecting method used of flavomycin $\mathrm{A}$ is equipped with uv detector of high performance liquid chromatograph (HPLC). In this study the method for determination of flavomycin in shrimp by high performance liquid chromatography was established. After chromatographic column separation, flavomycin drug was qualitative quantitative analysis using uv detector.

\section{Meterials and methods}

\section{Reagent and standards}

All other chemicals were of analytical grade and purchased at local resellers. Methanol, acetonitrile and $\mathrm{n}$-hexane were obtained from Merk. Buffer solution is $1000 \mathrm{ml}$ water solution which contain $3.0 \mathrm{~g}$ alkyl sulfonic acid sodium, $15.5 \mathrm{~g}$ potassium hydrogen phosphate and $1.0 \mathrm{~g}$ potassium dihydrogen phosphate. Then buffer was adjusted to $\mathrm{pH} 7.0 \pm 0.1$ with $20 \%$ phosphoric acid solution.

Flavomycin were purchased at China veterinary drug supervision. Flavomycin standard was dissolved with 1:1 methanol aqueous solution and configured to $1 \mathrm{mg} / \mathrm{mL}$ of standard stock solution. Working standard solutions (from 1 to $100 \mu \mathrm{g} / \mathrm{mL}$ ) were freshly prepared by dilution of the stock solution with methanol aqueous solution.

Mobile phases of several compositions were prepared by mixing ACN with buffer solutions, previously filtered through at $0.22 \mu \mathrm{m}$ nylon filter. 


\section{Instrumentation}

Separation and determination of flavomycin is normally performed by liquid chromatography with ultraviolet.(LC_UV). HPLC analysis was performed with an UV detector system (Agilent, USA).

\section{Preparation of standard solutions}

Quantification was based on the external standard method. Flavomycin was weighed $1 \mathrm{mg} / \mathrm{mL}$ standard stock solution of methanol aqueous solution was prepared. Dilutions of stock solution in methanol aqueous solution created working solutions for calibration and validation. All above solution was stored at $4^{\circ} \mathrm{C}$ prior to use. For the calibrator samples, final standard concentrations in different blank matrices were freshly prepared daily from working solutions with concentrations of $1-50 \mu \mathrm{g} / \mathrm{mL}$.

\section{Sample preparation}

Unknown grass carp specimens was performed by methanol aqueous solution, followed by a liquid-liquid extraction. Grass carp sample $(5 \pm 0.5 \mathrm{~g})$ was placed in $25 \mathrm{~mL}$ centrifuge tubes and extracted by methanol solution(1:1) by hand-shaking for one minute and centrifuged at $5000 \mathrm{r} / \mathrm{min}$ for ten minutes. The upper organic layer was transferred in another centrifuge tube . The slag was extracted again. Extraction was merged.The lower was defatted with n-hexane and cleaned through the membrane .Then the solution was determined by HPLC.

\section{Liquid chromatography-ultraviolet detection}

Chromatographic separation was performed on a Agilent RP-18 endcapped column (5 $\mu \mathrm{m}$, $150 \mathrm{~mm} \times 4.6 \mathrm{~mm})$. Gradient elution with a mixture of buffer solution $(1000 \mathrm{ml}$ water solution which contain $3.0 \mathrm{~g}$ alkyl sulfonic acid sodium, $15.5 \mathrm{~g}$ potassium hydrogen phosphate and $1.0 \mathrm{~g}$ potassium dihydrogen phosphate adjusted to $\mathrm{pH} 7.0 \pm 0.1$ with $20 \%$ phosphoric acid solution, solvent $\mathrm{A}$ ) and acetonitrile (solvent $\mathrm{B})(\mathrm{A}: \mathrm{B}=65: 35, \mathrm{~V} / \mathrm{V})$. At a flow rate of $1.0 \mathrm{~mL} / \mathrm{min}$, was applied. The temperature of the column was $40^{\circ} \mathrm{C}$. Detection was performed at an ultraviolet wavelength of $256 \mathrm{~nm}$.

\section{Data analysis}

The external standard calibration method was used for quantification. For each standard curve, five or six different concentrations were used.Peak area of the target analytes were calculated for each concentration. These data were fit to a linear least-squares regression curve with a weighting factor of $1 / x$.

\section{Results and discussion}

Extraction reagent . Flavomycin is organic weak acid, soluble in water, so methanol which can miscibility with water or methanol aqueous solution can be as extraction agent.. At the same time, adopt the method of ultrasonic heating can make solvent completely osmosis grass carp muscle tissue, promote the dissolution of flavomycin. This experiment was using pure methanol, 30\%, $50 \%, 70 \%$ methanol aqueous solution and water as extraction reagent At $50{ }^{\circ} \mathrm{C}$ heating ultrasound $30 \mathrm{~min}$ and compared extraction efficiency. Results showed that the recovery rates were similar. 
But $50 \%$ methanol extraction efficiency was slightly tall,so this experiment used $50 \%$ methanol resolution as extraction reagent.

With the method of liquid-liquid extraction by using the properties of flavomycin drug that flavomycin was not easy to dissolve in n-hexane. $10 \mathrm{ml}$ flavomycin standard solution was added to $50 \%$ methanol aqueous solution, the lower solution was detected after defatted with $5 \mathrm{ml}$ of n-hexane.Results show that the recovery was $99.6 \%$,. There is almost no loss.

Liquid chromatography parameters. This study Chose $\mathrm{C}_{18}$ column as chromatographic column which was more commonly used in high performance liquid chromatography (HPLC). Results found flavomycin can obtain the ideal separation effect on $\mathrm{C} 18$ chromatographic column. The mobile phase $\mathrm{pH}$, ion pair reagent concentration, velocity and ratio were optimized. Finally instrument conditions were determined. Chromatogram of flavomycin standard was shown in Fig. 1.

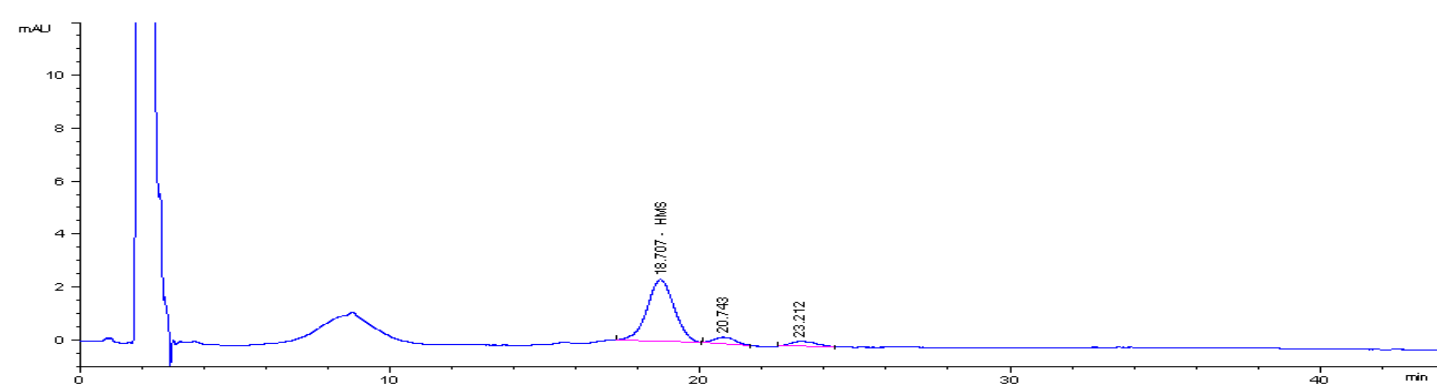

Fig. 1 Chromatogram of flavomycin standard at $10 \mu \mathrm{g} / \mathrm{mL}$

Method validation. The sensitivity of the method was evaluated by determining the limit of quantitation (LOQ). S/N is greater than 10 when plus scalar is $2 \mathrm{mg} / \mathrm{kg}$. In this condition, recoveries is greater than $70 \%$, and the precision is less than $10.4 \%$. Therefore $2 \mathrm{mg} / \mathrm{kg}$ was determined as limits for the quantitative detection of flavomycin.

The linearity of the method was evaluated by calculation of the regression line by the method of least squares and expressed by the coefficient of determination (R2). Based on residual plots a 1/x weighting factor was applied. The calibration curves were fitted with the concentration of 1-1000 $\mu \mathrm{g} / \mathrm{mL}$ in different matrix.Linear correlation coefficient of flavomycin was 0.997 .

Three concentrations of flavomycin standard solution were added to grass carp blank samples. Accuracy were determined by replicated analysis $(n=5)$ of sample.The precision of flavomycin ranged from4.40to $10.4 \%$. The average recovery of flavomycin ranged from $83.9 \%$ to $88.2 \%$. Accuracy and average recovery were shown in Table 1.

Table 1 Recoveries and precisions of flavomycin in grass carp

\begin{tabular}{|c|c|c|c|c|c|c|c|c|}
\hline \multirow{2}{*}{$\begin{array}{c}\text { added } \\
\text { concentration } \\
(\mathrm{mg} / \mathrm{kg})\end{array}$} & \multicolumn{6}{|c|}{$\begin{array}{l}\text { measured values } \\
\qquad(\mathrm{mg} / \mathrm{kg})\end{array}$} & \multirow{2}{*}{$\begin{array}{c}\text { average coveries } \\
(\%) \\
85.5\end{array}$} & \multirow{2}{*}{$\begin{array}{r}\text { precision } \\
\text { accuracy } \\
(\%) \\
4.40\end{array}$} \\
\hline & 1.63 & 1.71 & 1.64 & 1.72 & 1.71 & 1.84 & & \\
\hline 10.0 & 9.44 & 8.27 & 9.53 & 7.69 & 7.54 & 7.92 & 83.9 & 10.4 \\
\hline 50.0 & 47.5 & 40.9 & 43.2 & 42.8 & 44.5 & 45.6 & 88.2 & 5.25 \\
\hline
\end{tabular}




\section{Conclusion}

The method for quantification of flavomycin in grass carp was developed and validate.In this method,the solvent extraction was 1:1 methanol aqueous solution and sample was defatted with $\mathrm{n}$-hexane.The Liquid chromatography analysis was sensitive and specific. The average recovery of flavomycin at three concentrations are all more than $83.9 \%$.Precisions were less than $10.4 \%$.Method validation results for linearith,precision,accuracy and recovery were acceptable.The proposed procedure is applicable for flavomycin residues in aquatic products.

\section{References}

[1] F. Volkea, * R. Waschipkya and A. Pampela: Chemistry and Physics of Lipids Vol. 85 (1997), p.115-123.

[2] Sandra P'erez, Brenna E and McJury: Journal of Chromatography A Vol.1175(2007), p.234-241.

[3] Uwe Kempin,Lothar Hennig and Dietmar Knoll: Tetrahedron Vol. 53( 1997) , p.17669-17690.

[4] Sang-Hee Jeong*,Yun-Kyung Song and Joon-Hyoung Cho: Regulatory Toxicology and Pharmacology Vol. 53( 2009), p.209-216.

[5] Ernst BAUSE,Giinter LEGLER: Biochem. J Vol. 201( 1982) , p.481-487.

[6] Firman J D,Kim B N: PoIlltry Science Vol. 68( 1989) , p.1724-1726. 